NBER WORKING PAPER SERIES

\title{
PUBLIC HEALTH INSURANCE, PROGRAM TAKE-UP, AND CHILD HEALTH
}

\author{
Anna Aizer \\ Working Paper 12105 \\ http://www.nber.org/papers/w12105 \\ NATIONAL BUREAU OF ECONOMIC RESEARCH \\ 1050 Massachusetts Avenue \\ Cambridge, MA 02138 \\ March 2006
}

I am extremely grateful to Janet Currie. I also thank Karen Conway, Pedro Dal Bó, Angie Fertig, Jeff Grogger, Joe Hotz, Guido Imbens, Jeff Kling, and Chris Paxson as well as seminar participants at UCLA, UCI, Princeton and Brown Universities and the NBER Children's meeting. Jim Klein and Kennalee Gable of the California Department of Health Services generously provided the data. Financial support from the Social Science Research Council, Program in Applied Economics and the California Program on Access to Care is gratefully acknowledged. The views expressed herein are those of the author(s) and do not necessarily reflect the views of the National Bureau of Economic Research.

(C2006 by Anna Aizer. All rights reserved. Short sections of text, not to exceed two paragraphs, may be quoted without explicit permission provided that full credit, including $(\odot)$ notice, is given to the source. 
Public Health Insurance, Program Take-Up, and Child Health

Anna Aizer

NBER Working Paper No. 12105

March 2006

JEL No. I12, I18, I38, J13

\begin{abstract}
Of the ten million uninsured children in 1996, nearly half were eligible for Medicaid, the public health insurance program for poor families, but not enrolled. In response, policy efforts to improve coverage have shifted to increasing Medicaid take-up among those already eligible rather than expanding eligibility. However, little is known about the reasons poor families fail to use public programs or the consequences of failing to enroll. The latter is of particular relevance to Medicaid given that children are typically enrolled when they become sufficiently sick as to require hospitalization. Using new data on Medicaid outreach, enrollment and child hospitalizations in California, I find that information and administrative costs are important barriers to program enrollment, with the latter particularly true for Hispanic and Asian families. In addition, enrolling children in Medicaid before they get sick promotes the use of preventative care, reduces the need for hospitalization and improves health.
\end{abstract}

\author{
Anna Aizer \\ Brown University \\ Department of Economics \\ 64 Waterman Street \\ Providence, RI 02912 \\ and NBER \\ aizer@brown.edu
}


In 1996, ten million US children were without health insurance and nearly half a million children were hospitalized for conditions that could have been avoided had they had access to timely preventative care [Fronstin, 1998; Graves, 1998]. Such facts have often been used to support efforts to expand eligibility for public health insurance. However, nearly half of the ten million children without insurance were already eligible for Medicaid, the public health insurance program for poor families, but not enrolled [Selden, Banthin, and Cohen, 1998]. And evidence presented by Card and Shore-Sheppard [2005] suggests that recent Medicaid eligibility expansions have had a very limited impact on health insurance coverage precisely because of low take-up, not crowd-out. As a result, recent debate over improving health insurance coverage has shifted away from eligibility expansions to increasing enrollment or take-up among those already eligible but not enrolled.

However, little is known about the reasons nearly half of poor families fail to use public programs that involve no out-of-pocket costs. In a review of the existing literature on program take-up, Remler, Rachlin and Glied [2001] conclude that of the factors determining program (including Medicaid) participation "what little evidence about their effects exists is primarily qualitative and self-reported, based on focus groups and reports of officials. Their quantitative magnitude is entirely unknown.”

Yet the policy debate over Medicaid take-up also raises the question of whether early enrollment in Medicaid leads to gains in efficiency or health. Unlike the food stamp or cash welfare programs for which lack of program participation results in lack of any benefit, poor children who are eligible for Medicaid but who fail to enroll will be cared for (by law) should they become ill and require hospitalization. Not only will they be cared for, but their care will be covered by Medicaid since eligible uninsured children are nearly always enrolled in Medicaid when they present at the hospital. ${ }^{1}$ Thus, the potential benefit of early enrollment lies in its

\footnotetext{
${ }^{1}$ In California very few children are discharged from the hospital with no source of insurance listed. This is likely due to the fact that most hospitals in California (and elsewhere) have workers on-site to aid with
} 
promotion of the efficient use of health care resources by increasing financial access to ambulatory preventative care prior to hospitalization, resulting in fewer hospitalizations, better health and lower costs. However, estimation of the impact of Medicaid enrollment on health care utilization and child health is hindered by the endogeneity of the enrollment decision: children who are less healthy and thus in greater need of medical care and hospitalization are more likely to enroll.

Thus the purpose of this research is two-fold: 1) to better understand the causes of low take-up in public programs by studying the case of Medicaid, and 2) to determine whether greater Medicaid take-up improves access to primary preventative care and reduces the need for hospitalization. To answer these questions, I create a unique dataset for the state of California that combines information on the timing and placement of outreach efforts to increase Medicaid takeup with administrative data on Medicaid enrollment and hospitalization for the period 1996-2000 at a very fine level of detail (the zipcode and month). The California outreach campaign was launched in mid 1998 and consists of advertising a toll free hotline number and providing community-based application assistance that is often bilingual. Identification follows from the exogenous variation in both the placement and timing of the outreach, using geographic fixed effects to account for any potential selection in the placement of outreach.

I find the largest effects of outreach on those with the highest costs of enrolling: Hispanic and Asian children who have greater language and immigration concerns than other families. Proximity to an additional bilingual application assistant increases new monthly Medicaid enrollment among Hispanics by seven to nine percent and among Asian children by 27 to 36 percent. Advertising has a smaller impact on new enrollment than application assistance and its impact is slightly delayed. English language advertisements increase new Medicaid enrollment among all children in the following month by 4.7 percent and Spanish language advertisement

Medicaid enrollment. 
increases new enrollment among Hispanic children the following month by an additional 2.5 percent. These results have important implications not only for improving Medicaid coverage among poor children, but also for increasing take-up in other programs such as food stamps and the Earned Income Tax Credit (EITC).

In the second part of the paper, I use instrumental variable techniques to estimate the impact of early Medicaid take-up on access to primary care and avoidable hospitalizations. In the first stage I estimate the impact of outreach on Medicaid enrollment. In the second stage I estimate the impact of (predicted) Medicaid enrollment on avoidable hospitalizations. I define hospitalizations as avoidable if they are for "diagnoses for which timely and effective ambulatory care can help to reduce the risks of hospitalization by either preventing the onset of an illness or condition, or controlling an acute episodic disease or condition.”[ Billings and Teichholz,1990]. If families respond to local outreach efforts and enroll their children in Medicaid before they become sick, this should improve their access to regular ambulatory care and the number of avoidable hospitalizations should decline. I find that increased take-up leads to lower hospitalization rates for avoidable conditions but not others. IV results suggest that increasing the number of children with Medicaid by ten percent results in a two to three percent decline in avoidable hospitalizations among children.

The rest of the paper proceeds as follows: section I surveys the existing literature on outreach and Medicaid take-up and avoidable hospitalizations, section II provides background on California’s outreach program, section III presents implications of a model of Medicaid enrollment in the face of fixed enrollment costs, section IV describes the data, empirical strategy and results of the analysis of the effect of outreach on enrollment, section V presents the results of the analysis of the impact of increases in enrollment on avoidable hospitalizations, and section VI concludes.

\section{Existing Literature}




\section{A. Medicaid Take-Up}

Though Medicaid has no out of pocket costs, many poor families still fail to enroll: nearly half of all uninsured children in California in 1998 were eligible for Medicaid but not enrolled. The three main reasons for low take-up, as hypothesized in the literature, are 1) lack of information (information costs), 2) administrative hassle associated with an application that requires considerable paper-work, verification of income and visits with caseworkers (process costs), and 3) and stigma associated with public programs (outcome costs) [Craig, 1999].

What empirical work on Medicaid take-up exists consists largely of focus groups and case-studies, the results of which may not be generalizeable to the population of uninsured children. $^{2}$ Three qualitative studies of Medicaid take-up in California suggest that process and information costs are the main concerns for this population, particularly for immigrant populations who face language barriers and may have documentation concerns. ${ }^{3}$

\section{B. Avoidable Child Hospitalizations}

Eighteen to 28 percent of all child hospitalizations are avoidable or ambulatory care sensitive [McConnochie et al, 1997]. There is strong evidence that high rate of avoidable hospitalizations do reflect inadequate ambulatory care [Parchman and Culler, 1994; Shi et al (1999); Gill and Mainos (1998); Gadmoski, 1998; Epstein, 2001]. ${ }^{4}$

\footnotetext{
${ }^{2}$ Focus groups on Medicaid enrollment in California revealed that confusion over eligibility, language barriers, fears about immigration and an onerous enrollment process were considered important barriers by eligibles [Perry, Stark and Valdez 1998; Perry 2001]. Other research concludes that the enrollment process (long applications and waiting periods) represents a greater barrier to enrollment than concerns related to eligibility, coverage, benefits, costs, physician availability and documentation requirements [Medi-Cal Policy Institute, 2000].

${ }^{3}$ Immigration concerns consist of fears of deportation among those in the US without proper documentation and for those with documentation, fears of being considered a "public charge" which could lead to deportation.

${ }^{4}$ For example, Parchman and Culler [1994] find that areas with more general practice physicians have lower rates of avoidable hospitalizations, controlling for other environmental characteristics that might affect hospitalization rates. Shi et al [1999] find that those children without a primary care provider were nearly ten times more likely to be hospitalized for an ACS condition than those with a primary care provider.
} 
Linking avoidable hospitalizations to insurance coverage, however, has proven more difficult because of unobserved characteristics correlated with both the insurance decision and medical care utilization. If underlying factors, such as initial health status, care-seeking behavior, or poverty, are associated with Medicaid enrollment and with avoidable hospitalizations, then Medicaid enrollment is endogenous, complicating estimation of its impact on hospitalizations. Work by Kaestner, Joyce and Racine [1999] and Dafny and Gruber [2005] represent the two best efforts to control for these factors in estimates of the impact of Medicaid eligibility expansions on child hospitalization. The authors identify the effect of expanding Medicaid eligibility to previously ineligible children by using variation across states over time (as the Medicaid expansions were implemented at different times in different states. $)^{5}$ Kaestner, Joyce and Racine [1999] find mixed evidence regarding the impact of Medicaid eligibility expansions on avoidable hospitalizations, concluding that there is "at best weak support for the hypothesis that Medicaid improves the health of low income children.” Dafny and Gruber [2005] find that expanding Medicaid eligibility increases the total number of hospitalizations, but that the increase was mitigated by a much smaller (and statistically insignificant) increase in avoidable hospitalizations.

The question raised and answered in this paper, however, differs from both these two papers which can explain the different results. In this paper I estimate the impact not of expanding eligibility to additional children, but of increasing program take-up among children already eligible. Those made eligible for Medicaid through program expansions gain access to both inpatient and ambulatory care which may have opposing effects on avoidable hospitalizations: the former may raise all hospitalizations (including avoidable ones), while the latter may reduce them. A priori, it is not clear which dominates, though the evidence on eligibility expansions presented by Kaestner, Joyce and Racine [1999] and Dafny, Gruber [2005] suggests that the increase in access to inpatient care is at least as great as the increase in access to

\footnotetext{
${ }^{5}$ Their method relies on the inclusion of state and time fixed effects to control for unobservables correlated with Medicaid coverage and hospitalization rates. They also exploit some within state*year variation as
} 
ambulatory preventative care. In contrast, the impact on hospitalization of an outreach campaign that targets those who already have access to inpatient care but stand to gain access to ambulatory care is unambiguously negative. This can explain why, unlike previous work on eligibility expansions, I find that increasing take-up reduces avoidable hospitalizations. ${ }^{6}$ A second difference between this work and that of previous work is that I use considerably more detailed data (outreach, enrollment and hospitalization at the zipcode level versus state level), enabling me to control for many factors, observed and unobserved, that vary at a local level and may affect both Medicaid enrollment and child health. In addition, I use a novel instrument to identify the impact of Medicaid enrollment on child hospitalizations.

\section{Background on Medicaid and Outreach in California}

\section{A. Medicaid Eligibility}

Children in California qualify for Medicaid through multiple channels. The most common channel (67 percent of all Medicaid covered children in 1996) is through the cash welfare program - AFDC/TANF. All children on welfare are automatically eligible for Medicaid and thus face zero costs of enrollment in Medicaid. The next most common means of Medicaid enrollment among children are through the Medicaid poverty expansion and medically needy programs, and, more recently, the federal section 1931(b) program. The outreach programs developed by the state target families eligible through all non-welfare mechanisms. ${ }^{7}$

the Medicaid expansions included children of some ages, and not others.

${ }^{6}$ One could argue that if eligible children do not know they are eligible, then an outreach campaign would have the same effect as an eligibility expansion in terms of increasing access to inpatient care as well. If that were the case, then an outreach campaign might increase hospitalizations, contrary to these findings.

${ }^{7}$ In California, the poverty expansions extend Medicaid eligibility to infants up to $200 \%$ of the federal poverty level (FPL), children under 6 up to 133\%, children 6-15 up to $100 \%$ and children ages 15 and older up to $82 \%$ of the FPL. California's medically needy program is a relatively generous program, providing coverage to families with income roughly one third higher than current AFDC/TANF levels. The 1931(b) program (implemented in January 1998) stipulates that all families with income below 100 percent FPL are eligible for Medicaid. For most children (except those age 15 and older) 1931(b) did not 


\section{B. Trends in Child Medicaid Enrollment}

Child Medicaid enrollment in California has been declining since 1995 [California Medical Assistance Program, Annual Statistical Report, 2000]. The driving force behind the decline in Medicaid enrollment has been drastically falling welfare rolls in California that have been partially offset by a rise in children enrolled through other non welfare-related channels beginning in mid 1998, coincident with the implementation of the state's outreach program in June of that year (Figure I). This suggests that the rise in non welfare-related Medicaid enrollment does not simply reflect a transfer of enrollment from welfare-related enrollment as welfare caseloads decline, but is likely linked to outreach launched in mid 1998. For Hispanic children, the increase in enrollment beginning in 1998 was particularly large, resulting in a net increase in total Hispanic Medicaid enrollment between 1998 and 2000 (Figure II).

\section{California’s Uninsured and the Medicaid Outreach Campaign}

A 1999 study of the uninsured in California estimated that of the 1.8 million uninsured children in the state, nearly 800,000 were eligible for Medicaid and among those eligible, 60 percent were Hispanic. ${ }^{8}$ Low rates of take-up among the Hispanic population are consistent with their facing greater costs of enrolling due to language barriers and/or immigration concerns.

California’s outreach campaign was launched in June, 1998 coincident with the launching of the state's SCHIP program, entitled Healthy Families, which expanded coverage to children in families with income above Medicaid eligibility thresholds but below 250 percent of the federal poverty level through a separate, non-Medicaid program. The outreach campaign targets both the 800,000 uninsured children eligible for Medicaid but not enrolled and an additional 325,000 newly eligible for Healthy Families. The outreach campaign is comprised of two main components discussed in turn below.

${ }^{8}$ This study was conducted by the UCLA Center for Health Policy and based on the 1998 March CPS. 


\section{Community Based Application Assistants (CBOs)}

Community based application assistants (CBOs) are non-profit community organizations that are trained by the state in the completion of Medicaid applications. This component of the outreach campaign is designed to lower the process or application costs of enrollment and the state budgeted $\$ 6.7$ million for CBOs in the first year. ${ }^{9}$ CBOs do not represent new organizations placed in the community for the purpose of conducting outreach and enrollment, but are pre-existing organizations that are trained and authorized by the state to assist their clients in the completion of Medicaid applications. ${ }^{10}$ For all applications received and approved by the state, a $\$ 50$ fee is granted to the application assistant, providing a financial incentive to enroll children. ${ }^{11}$ Nearly half of the 1,100 CBOs providing assistance in the first year of the program were health care providers and clinics (hospitals are not eligible), 20 percent were community service organizations and nine percent were schools. Half of the CBOs have bilingual staff. According to information provided by a subset of the CBOs, CBOs primarily serve one ethnic/racial group.

Over time, access to CBOs has increased. In 1998, 28 percent of all zipcodes had a participating CBO (Appendix Table 1A). CBOs in the most disadvantaged areas (lower per capita income, fewer high school graduates and fewer white families) appear to have been the first to participate (Appendix Table 1B). Over time, as CBO participation increased, the percent of zipcodes with a CBO increased to 39 by 1999 and 46 by 2000, with the newest CBOs located in less disadvantaged areas. By March of 1999, ten months after the campaign was launched, half of all Medicaid applications received by the state were completed with the assistance of a

\footnotetext{
${ }^{9}$ In the first year, \$2.1 million was allocated for the payment of the \$50 fee, \$1.9 for training and \$2.7 for support.

${ }^{10}$ CBOs become certified as application assistants by the state prior to their submitting any applications, thereby mitigating the possibility that the estimated impact of CBOs on enrollment is demand-driven.

${ }^{11}$ Kopczuk and Pop-Eleches (2005) find evidence that providing financial incentives to tax preparers increases participation in the EITC program.
} 
community based organization and over $\$ 1$ million in application assistance fees had been paid to CBOs.

Figure III presents trends in non welfare-related Medicaid enrollment among Hispanics that gain access to one, two to four, and five or more CBOs over this period. Differences in initial levels between these groups exist, but the time trends in enrollment prior to the launching of the campaign appear the same across all areas. However, beginning in June 1998, the differences in non welfare-related Medicaid enrollment among these groups increased proportionately with the number of CBOs located in those areas. Hispanics living in areas that gain access to greater numbers of CBOs exhibited a greater increase in enrollment relative to Hispanics that gained access to fewer numbers of CBOs. The non random placement of CBOs suggests possible selection on location which I address in Section IV.

\section{The State Advertising Campaign}

The state advertising campaign consists of English and Spanish television advertisements that run in 48 of the state's 58 counties. The advertising campaign was launched in June, 1998 and in the first 30 months of the program, television advertisements were aired in at least one county in all but seven months. All campaign materials consistently promote the toll-free number which is staffed Monday - Friday 8am to 8pm by a team of operators proficient in ten languages who respond to requests for applications, assist with questions about the application, and provide referrals to CBOs.

The campaign cost \$7 million in the first year. The state largely considers the state-wide media campaign a success, based on the fact that calls to the toll-free hotline double in the weeks during which commercials have aired (from roughly 800calls/day to 1900 calls/day), and that 30 percent of callers identified advertising as their primary source of information about Medicaid. However, the state does not know what proportion of calls result in application and enrollment. 


\section{Medicaid Enrollment and Selection}

There are two main implications of a simple economic model of enrollment in Medicaid which lowers the cost of purchasing medical care but includes fixed costs of participation. First, if the fixed costs of participation decrease (through, for example, an outreach campaign), families will be more likely to participate. For those for whom the cost decrease is greater as a result of outreach (Hispanic and Asian families with language barriers and immigration concerns), the probability of enrollment will likewise be greater. Second, given the likelihood of negative correlation between underlying (and unobserved) health and enrollment (those sickest are most likely to enroll), OLS regression of hospitalization on Medicaid coverage will result in upward biased estimates of the impact of Medicaid coverage on hospitalization. However, as the costs of enrollment decrease with outreach, the average health of those enrolling will increase. Thus instrumenting for Medicaid coverage using outreach should reduce or eliminate this selection bias.

\section{The Effect of Outreach on Medicaid Enrollment}

\section{A. $\underline{\mathrm{CBOs}}$}

\section{Data and Empirical Strategy}

To assess the impact of lowering process costs on new Medicaid enrollment, I link data on CBO placement with data on new Medicaid enrollment by zipcode, race, and month for February 1996 to December 2000 among all children age 0 to 15. Administrative data on Medicaid enrollment for all children in California includes information on the child's age, race/ethnicity, zipcode of residence, type or mechanism of Medicaid eligibility (welfare-related, SSI, 1931(b), etc.) and month of enrollment. I define enrollment as new if the individual had not been enrolled in Medicaid in the past month, thereby excluding those children who have 
transitioned off welfare onto other Medicaid coverage. I also exclude all children eligible through foster care and supplemental security income (SSI) as Medicaid coverage is automatic for these populations. The data are collapsed to zipcode-year-month-race cells. If there were no zero cells, this would yield a sample size of $480,000 .^{12}$ However, due to some zero cells (zipcodes with no low-income children of a given race), the final data set consists of 390,379 cells. Weights are generated by calculating the number of children in each zipcode in families with income below 200\% FPL from the 2000 Census. Sample means (calculated for each zipcode and month and weighted) are provided in Appendix Table 2. In a (low income population weighted) average zipcode-race-month cell, there are 67 new monthly Medicaid enrollees, most of whom enroll through non welfare-related programs. ${ }^{13}$ Among Hispanic children, there are on average, 140 new Medicaid enrollees per zipcode per month.

CBO availability or access is defined as the number of CBOs in one's zipcode as of the first month of enrollment. Because Medicaid coverage begins on the date of application, this is equivalent to access to CBOs as of the date of application. To isolate the effect of outreach on take-up among those already eligible but not enrolled separate from eligibility expansions, I include only those children whose eligibility did not expand over this period. Thus children made newly eligible through the SCHIP program Healthy Families and children age 15-19 who witnessed a small increase in eligibility over this period through the 1931(b) program (from 82 to 100 percent of the FPL) were excluded.

To identify the impact of CBOs on Medicaid enrollment, I employ multiple strategies to account for possible selection in their placement or timing that may be based on demand for these services. First, zipcode, year and month fixed effects are included to control for the fact that areas with more intense outreach efforts may have higher numbers of low-income children, and general trends in enrollment over this time period, respectively. Also included are other

\footnotetext{
121600 zipcodes*5 races*5 years*12 months.

13 The unweighted means of monthly new enrollment are 9.4, 6.5 and 2.9 for total, non-welfare and welfare
} 
covariates that control for changes in the business cycle and in the underlying demographic composition of the state that may affect the demand for health insurance. The basic equation has the following form:

$$
\begin{aligned}
\mathrm{M}_{\mathrm{rzmy}}= & \beta_{0}+\beta_{1} \text { ENGCBO }_{\text {zmy }}+\beta_{2} \text { SPCBO }_{\text {zmy }}+\beta_{3} \text { ASNCBO }_{\text {zmy }}+\beta_{4} \text { HISP }^{*} \text { SPCBO }_{\text {rzmy }} \\
& +\beta_{5} \text { ASIAN*ASNCBO }_{\text {rzmy }}+\beta_{6} \text { RACE }_{\mathrm{r}}+\beta_{7} \text { BIRTHS }_{\text {rzmy }} \\
& +\beta_{8} \text { UNEMP }_{\text {cy }}+\beta_{9} \text { INC }_{\mathrm{cy}}+\beta_{10} \text { MONTH }_{\mathrm{m}}+\beta_{11} \text { Year }_{\mathrm{y}}+\beta_{12} \text { ZIPCODE }_{\mathrm{z}}+v_{\text {rzmy }}
\end{aligned}
$$

$\mathrm{M}_{\mathrm{rzmy}}$ is new Medicaid enrollment for race $\mathrm{r}$ in zipcode $\mathrm{z}$ in month $\mathrm{m}$ and year $\mathrm{y}$. $\mathrm{ENGCBO}_{\mathrm{zmy}}$ is the number of community based application assistants without bilingual staff in the zipcode in the month of enrollment, $\mathrm{SPCBO}_{\text {zmy }}$ is the number of CBOs with Spanish-speaking staff. Spanishspeaking CBOs are interacted with a dummy for Hispanic (HISP ${ }_{\mathrm{r}} \mathrm{SPCBO}_{\mathrm{zmy}}$ in the above equation), while Asian speaking $\mathrm{CBOs}\left(\mathrm{ASNCBO}_{\text {zmy }}\right)$ are interacted with a dummy for Asian, $\left(\mathrm{ASIAN}_{\mathrm{r}} * \mathrm{ASNCBO}_{\mathrm{zmy}}\right)$. There are numerous Asian groups with different languages in California (Chinese, Japanese, Korean, Vietnamese, etc.). Grouping them together is justified because Asians from different countries tend to be highly geographically segregated in California and as such, the CBOs with Asian bilingual staff tend to serve one group primarily (this is also confirmed by self-reports of populations served provide by a subset of the CBOs). In addition I include race (Black, Hispanic, Asian and other race) indicators, controls for county unemployment rates $\left(\mathrm{UNEMP}_{\mathrm{cy}}\right)$ and per capita personal income $\left(\mathrm{INC}_{\mathrm{cy}}\right)$ as well as counts of the number of births to women with less than a college degree to control for changes in the

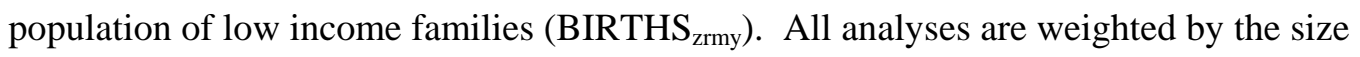
(population) of the cell as defined previously and the standard errors are adjusted for serial correlation within zipcode (clustered at the zipcode).

In additional specifications, I include further controls (zipcode*year fixed effects) to account for the possibility of selective timing and placement of CBOs that may bias the results.

related enrollment. 
include. This limits the identifying variation to changes in access to CBOs that occur within a relatively short period, thereby minimizing potential unobserved underlying differences between those areas that quickly gained access to a CBO and those with delayed access. The model is still identified since zipcodes gained access to CBOs throughout each year. To control for the possibility that Hispanic and Asian families residing in areas that gain access to bilingual CBOs may differ from those who do not, I interact Hispanic and Asian children with an indicator for whether they ever gained access to a CBO: Hisp*EverSPCBO and Asian*EverASNCBO. Finally, I include zipcode*year*month fixed effects to control for zipcode-specific changes over time in enrollment patterns. These fixed effects subsume the English only CBOs and the main effects of the bilingual CBOs.

Results: The Impact of CBOs on New Medicaid Enrollment

In Table 1 are estimates of the impact of CBOs on new non-welfare Medicaid enrollment (columns 1-4). The first column contains zipcode, month and year fixed effects (equation 1a). As is evident from the table, the greatest effects are those found for bilingual CBOs on Hispanic and Asian enrollment (Spanish language $\mathrm{CBO}^{*}$ Hispanic and Asian language $\mathrm{CBO}^{*}$ Asian). The estimates suggest that an additional Spanish language CBO increases total new monthly Medicaid enrollment for Hispanic children by nine percent, while an additional Asian language CBO increases enrollment by 27 percent among Asian children. ${ }^{14}$ Interestingly, the main effects of bilingual CBOs are negative and significant, though small, for Spanish and Asian language CBOs (-2.815 and -0.352). This suggests the possibility of selection effects in the timing and/or location of outreach efforts with outreach placed in those areas with declining enrollment. Columns two through four of Table 1 contain estimates from regressions that include increasingly restrictive controls. Column two includes zipcode*year and month fixed effects and column three

\footnotetext{
${ }^{14}$ Calculated as follows for Hispanic children: $(12.76-2.82) / 109=0.09$.
} 
includes zipcode*month*year fixed effects. Finally, the last column contains, in addition to zipcode*month*year fixed effects the additional variables - ever gain access to a Spanish CBO*Hispanic and ever gain access to an Asian CBO*Asian. These fixed effects control for the possibility that Hispanics and Asians in zipcodes that gain access to a CBO differ significantly from those who do not. When these additional controls are included, the coefficient on the interaction term for Hispanics declines while the interaction term for Asians increases slightly. Estimates based on the most restrictive regressions suggest that proximity to a bilingual CBO increases new enrollment by seven percent among Hispanics and 36 percent among Asians. In column 5, I present estimates of the impact of CBOs on welfare-related enrollment including the same set of controls as in column 4. As expected, the impact is significantly smaller in size, but there is still a small positive effect. It is possible that CBOs, as social service providers trained in the completion of Medicaid applications may also assist their clients in the completion of welfare applications. This could explain the small positive impact on Medicaid enrollment through welfare.

In Table 2 are estimates of the impact of CBOs on the natural log of new non-welfare related enrollment. In a natural log specification, the fixed effects will have the same proportional impact on each cell. For these regressions, I limit the sample to large cell sizes (more than 250 low income children) that have no zero observations in the first three columns and in the last colum I simply add one to every outcome to avoid dropping any cells (and thus any bias that might arise from selection on certain cells). For Asian and Hispanic children, gaining access to a bilingual CBO increases enrollment by roughly 14 and 12 percent, respectively, based on the most restrictive regression estimates.

I also explore whether the impact of CBOs varies by the type of CBO and by age of the child. CBOs that are health care providers have a greater incentive to enroll children - in addition to the $\$ 50$ fee, the medical care they provide these children will now be reimbursed by 
the state. In Table 3 I present estimates of the impact of CBOs that are health care providers on enrollment. As expected, providers appear to have considerably larger effects on enrollment than the average $\mathrm{CBO}$ - with new enrollment roughly double that of the average CBO. In Table 4, I present estimates of the impact of CBOs by age of the child: infant, preschool age and 6-15. The effects appear smallest for infants, perhaps because many infant are typically enrolled in Medicaid by the hospital at time of birth and the regressions include controls for the number of births to women with less than college. The largest effects appear for the oldest children - those age 6-15, perhaps because younger children are required to visit the doctor periodically for immunizations, providing an incentive for enrollment that is absent for older children.

Finally, in order to explore the possibility that the effect of CBOs is non- linear in nature and whether there may be diminishing returns, I present estimates of the impact of the first CBO, second CBO, etc. on new non welfare-related enrollment in Table 5. In the first column, I present estimates for new (non-welfare) monthly enrollment and in the second column, the dependent variable is the log of new monthly enrollment. These regressions include the most restrictive sets of controls. The results suggest that the impact is roughly linear for Spanish CBOs, but slightly concave for Asian CBOs.

In regressions not presented here, I aggregate the data to a broader level (a minor civil division which is a city or town) to account for the fact that individuals located near (but not in) zipcodes with a CBO also have access to application assistance. ${ }^{15}$ The results of this extension suggest that having access to a CBO within one's city or town increases enrollment one tenth as much as having one in one’s zipcode.

Between 1997 and 2000, enrollment in non-welfare related Medicaid increased 23 percent for Hispanics and 110 percent for Asians. Calculations based on results presented here suggest that outreach was responsible for 80 and 69 percent, respectively, of these increases in enrollment.

\footnotetext{
${ }^{15}$ There are 58 counties in California, 1600 zipcodes and 422 minor civil divisions.
} 


\section{Spillover from Eligibility Expansions}

Some spillover from SCHIP to Medicaid may have occurred from families who applied to SCHIP only to learn that they were eligible for Medicaid. However, the identification strategy employed is based on within state variation only. Any SCHIP spillover effects that affect the entire state equally will be subsumed in the time fixed effects (year and month). If, however, outreach was greater in areas that witnessed bigger increases in eligibility and thus increased demand for Medicaid overage, this would confound the effect of outreach. Measuring changes in eligibility at the zipcode level over a short period time is difficult because of data limitations. However, I can examine whether CBOs are located in areas with greater declines in welfarerelated Medicaid coverage that may affect the underlying demand for non welfare-related Medicaid coverage. I find that bilingual CBOs are placed in poor areas that are characterized by higher initial levels of welfare use (among all groups, not just Hispanics), but the rates of decline appear similar for those in areas without CBOs. In addition, I also examine trends in the number of births to women with a high school degree ore less (a significant predictor of poverty and a proxy for the number of low income families in an area) by race, zipcode and month. I find no evidence that CBOs locate in areas with increased growth in the number of poor families (see Figure IV).

\section{B. ADVERTISEMENTS}

\section{Data and Empirical Strategy}

To assess the influence of advertisements on new Medicaid enrollment, data on the timing of advertisements was linked to monthly Medicaid enrollment. The following equation was estimated: 


$$
\begin{aligned}
\mathrm{M}_{\text {rzmy }}= & \beta_{0}+\beta_{1} \text { ENGADVT }_{\text {zmy }}+\beta_{2} \text { SPADVT }_{\text {zmy }}+\beta_{3} \text { HISP }^{*} \text { SPADVT }_{\text {rzmy }}+ \\
& \beta_{4} \text { RACE }_{\mathrm{r}}+\beta_{5} \text { MONTH }_{\mathrm{m}}+\beta_{6} \text { YEAR }^{*} \text { ZIPCODE }_{\text {zy }}+\beta_{7} \text { BIRTHS }_{\text {rzmy }}+\varepsilon_{\text {rzmy }}
\end{aligned}
$$

$\mathrm{M}_{\mathrm{rzmy}}$ is new non welfare related Medicaid enrollment of race $\mathrm{r}$ in zipcode $\mathrm{z}$ in month $\mathrm{m}$ and year

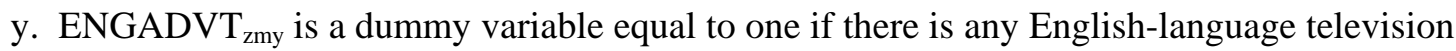
advertising in the month of enrollment, SPADVT bilingual (English and Spanish language) television advertising in the month of enrollment. The analysis is conducted at the level of the zipcode to allow more detailed controls and the standard errors are adjusted to account for the fact that advertising is determined at the level of the media market which is larger than a zipcode (eg, clustered by media market). ${ }^{16}$ Observations from 10 mostly rural counties in which advertisements were never aired are excluded from the dataset because they are so different. The final dataset consists of 336,334 observations. To ascertain whether advertising has an immediate effect on enrollment, or whether the effect is lagged, I also estimate the impact of television advertisements in the month before enrollment. Finally, as a check, I also estimate the impact of advertising in the month after enrollment - for which we expect no significant effect.

\section{Results: the Impact of Advertising on New Medicaid Enrollment}

The first column of Table 6 contains estimates of the impact of advertising (in English and Spanish) in the current month on new non welfare Medicaid enrollment. There does not appear to be any significant effect of advertising in the month of enrollment. In column two are estimates of the impact of advertising in the month before enrollment. Advertising in the month before enrollment does appear to have a small but significant impact on enrollment. In the month after English advertisements have aired, new monthly enrollment in Medicaid increases by nearly

\footnotetext{
${ }^{16}$ There are 12 media markets (DMAs) in California: Bakersfield, Chico, El Centro, Eureka, Fresno, Los
} 
4 percent. The main effect of Spanish language advertisements is negative (-0.883) but

imprecisely estimated. The effect of Spanish language advertisements on Hispanics, however, is positive and significant (1.828) but small, leading to just an additional one percent increase in non welfare related Medicaid enrollment among Hispanic children. In column (4) are estimates of past, current and future advertising on Medicaid enrollment. Neither current nor future advertisements appear to have any significant effect on Medicaid enrollment. The only significant effects are those for past English advertisements and the interaction of past Spanish language advertisements with Hispanic. English advertising in the previous month increases new monthly Medicaid enrollment by 4.7 percent and Spanish language advertisements increase enrollment among Hispanic children by an additional 2.5 percent. Thus, advertising appears to have a delayed impact on Medicaid enrollment.

\section{The effect of Outreach and Enrollment on Avoidable Hospitalizations}

In this section I examine whether early enrollment in Medicaid improves access to primary preventative care. To do so, I estimate the impact of Medicaid enrollment on avoidable or ambulatory care sensitive hospitalizations instrumenting for Medicaid with outreach efforts. Recall that hospital admissions are defined as avoidable or ambulatory care sensitive (ACS) if they are for "diagnoses for which timely and effective ambulatory care can help to reduce the risks of hospitalization be either preventing the onset of an illness or condition, controlling an

acute episodic disease or condition” [Billings and Tiecholz, 1990]. ${ }^{17}$ Thus, if early enrollment in Medicaid increases access to primary preventative care, we should see a decline in avoidable or ambulatory care sensitive hospitalizations in the following months.

\section{A. Data and Empirical Strategy}

Angeles, Monterey, Palm Springs, Sacramento, San Francisco, Santa Barbara and San Diego. 
Data on all child hospitalizations in the state of California for the period 1996-2000 were combined with data on Medicaid enrollment and outreach. The hospitalization data includes age, race, zipcode of residence, year and quarter of admission. Data on Medicaid enrollment for a given race in a given zipcode at the beginning of each quarter (January, April, July and October) are linked to admissions for that race and zipcode occurring in that quarter (eg, Medicaid enrollment as of the first of January are linked to all admissions in January, February and March of that year). The equation estimated has the following form:

$$
\begin{aligned}
& \mathrm{H}_{\text {rzqy }}=\beta_{1} \text { Medicaid }_{\text {rzqy }}+\beta_{3} \text { Race }_{\mathrm{r}}+\beta_{4} \text { Quarter }_{\mathrm{q}}+\beta_{5} \text { AdultAdm }_{\text {rzqy }}+\beta_{6} \text { AFDC/TANF }_{\text {rzqy }} \\
& +\beta_{7} \text { Zipcode* } \text { year }_{\mathrm{zy}}+\beta_{8} \text { Hisp*EverSPCBO }_{\mathrm{rz}}+\beta_{9} \text { Asian*EverASNCBO } \mathrm{rz}+\varepsilon_{\mathrm{rzq}}
\end{aligned}
$$

$\mathrm{H}_{\mathrm{rzqy}}$ is the number of avoidable (ACS) child hospitalizations in a given race, zipcode, quarter and year defined two ways: 1) over children with Medicaid as the listed source of payment, and 2) over all children, to avoid any sample selection. Medicaid in the above equation represents the stock of Medicaid enrollment for a given race and zipcode as of the first day of the quarter. Other controls include adult admissions for ACS hospitalizations (AdultAdm) to control for underlying trends in diseases or propensity to hospitalize that may vary over time or across groups. Ideally, I would include changes in income by race and zipcode over this period as the relationship between income and health is well-established, but such data are not available. Instead, I include welfare caseloads (AFDC/TANF), a proxy for changing income which also enables one to isolate the impact of outreach on Medicaid enrollment through non-welfare related channels (however, the inclusion of welfare caseloads does not alter the results.) To control for the fact Hispanic and Asian children residing in zipcodes that gain access to a CBO may differ in ways unobserved to the researcher that might affect both enrollment and propensity to hospitalize, the interaction

\footnotetext{
${ }^{17}$ Ambulatory care sensitive conditions include asthma, bronchitis, bacterial pneumonia, dehydration, cellulites and ear infections.
} 
terms Hisp*EverSPCBO and Asian*EverASNCBO are also included, as they were in previous regressions of the impact of CBOs on new enrollment. Finally, zipcode*year fixed effects are also included subsuming all annual county level employment and income measures.

Zipcode*year*quarter fixed effects are included in the last set of regressions, representing the most restrictive controls for all variables, observed and unobserved, that vary from year to year within zipcode.

As noted previously, because children in need of hospitalization are more likely to enroll in Medicaid we would expect OLS estimates to be biased upward. To overcome this bias, I use outreach efforts as instruments for the stock of Medicaid enrollment in the first stage. Specifically outreach is defined as the number of CBOs available in one's zipcode as of the start of the quarter. ${ }^{18}$ Outreach is likely to affect the stock of Medicaid enrollment by increasing both the number of new enrollees and the probability of re-enrollment, given the high rates of turnover in Medicaid.

In the first stage I estimate the impact of provider CBOs, non-provider CBOs and all CBOs on the stock of Medicaid enrollment and present the results in columns 1, 2 and 3, respectively of Appendix Table 3. The decision to stratify by CBO type is based on the fact that previous results suggest that provider CBOs have a greater impact on enrollment as well as the fact that IV results with respect to avoidable hospitalizations may vary with CBO type. How they vary, however, is unclear. One the one hand, we might expect access to primary care to improve more if enrollment is through a provider - resulting in a bigger decline in avoidable hospitalizations. On the other hand, it might be the case that those who enroll though a provider are more likely to be in worse health and thus more likely to be hospitalized - resulting in a smaller decline in avoidable hospitalizations.

\footnotetext{
${ }^{18}$ Advertisements are not used because of the relatively small impact on enrollment. In addition, using advertisements at the start of the quarter as an instrument is problematic given that the stock of Medicaid enrollment is affected by advertisements in both current and past months. Presence of CBOs in current and past months is correlated, but advertisements are not.
} 
Consistent with previous findings with respect to new enrollment, provider CBOs have a greater impact on the stock of Medicaid enrollment (Appendix Table 3). The results from the first stage suggest that access to one Spanish speaking CBO clinic increases Medicaid enrollment among Hispanic children by 11 percent while access to any Spanish speaking CBO (not necessarily a clinic) increases enrollment by seven percent. ${ }^{19}$ The impact of access to one Asian language CBO increases Medicaid enrollment by 20 percent among Asians. The main effect of Spanish language CBOs is negative and significant, suggesting possible omitted variable bias/endogeneity regarding the placement and/or timing of CBO placement. In columns 4, 5 and 6 I present estimates of the first stage regression in which zipcode*year*quarter fixed effects are included (these fixed effects will control for omitted variables that vary within zipcode over time and subsume the main effects of English-only, Spanish and Asian language CBOs). When the most restrictive controls are included, the estimated coefficients on the interaction terms remain unchanged.

\section{B. Results}

OLS and IV regression estimates of the impact of Medicaid enrollment on ACS hospitalizations are presented in Table 7. The first three columns display results from a regression of the impact of Medicaid enrollment on all child ACS hospitalizations. The first contains OLS results, the second results from an IV regression in which only clinic/provider CBOs (IV-Clinic) are used as instruments in the first stage and the third column contains results from an IV regressions in which all CBOs are used as instruments in the first stage (IV-All). The OLS results suggest that a 10 percent increase in Medicaid enrollment leads to a 1.6 percent decline in ACS hospitalizations. The instrumented results suggest that such an increase leads to a 2.9 percent reduction in hospitalizations if only clinics are used as instruments and a 1.8 percent

\footnotetext{
${ }^{19}$ Average (non Welfare) Medicaid enrollment among Hispanic children is 2094. Increasing access to 1 Spanish-speaking CBO will increase enrollment by 222 (339-117), roughly 11 percent.
} 
reduction when all CBOs are used as instruments. This suggests that access to a provider CBO is more effective in increasing access to ambulatory care. The results for Medicaid ACS hospitalizations (columns 4-6) are very similar. Though the point estimates are smaller, the effects (in percent terms) are slightly larger: a 10 percent increase in Medicaid enrollment leads to between a 2.3 and 3.4 percent decrease in Medicaid ACS hospitalizations, with larger effects for clinic CBOs. In columns 7-9 are OLS and IV estimates of the impact of Medicaid enrollment on marker conditions - hospitalizations which should not be affected by access to primary care such as congenital heart defect, appendicitis and some forms of cancer. Medicaid enrollment has no significant impact on hospitalization for markers in either OLS or IV regressions. Finally, in columns 10-12 are estimates of regressions in which zipcode*year*quarter fixed effects are included (the first stage results are in columns 4-6 of Appendix Table 3). The estimated coefficients are very similar: a 10 percent increase in Medicaid enrollment leads to between a 1.8 and 2.8 percent decline in ACS hospitalizations.

It is possible that in addition to affecting the probability of admission, early enrollment might also affect one's treatment once hospitalized. To explore this possibility, I estimate the impact of early enrollment on the length of hospitalization and present the results in the second panel of Table 7. Columns 1 through 3 show the OLS and IV results for the impact of early enrollment on average length of stay for all child hospitalizations, columns 4 through 6 show similar results for Medicaid hospitalizations. There seems to be only weak evidence that early enrollment in Medicaid reduces length of stay in the hospital. OLS estimates suggest that a ten percent increase in Medicaid enrollment reduces average length of stay by 0.5 percent while the IV-Clinic results are more than twice as large, but imprecisely estimated. These small effects may be due to the fact that increases in Medicaid take-up are likely to reduce hospitalizations among the least sick, and thus those who continue to be hospitalized after increased Medicaid take-up will be, on average, sicker and more likely to need more hospital care, thus resulting in longer hospital stays. 


\section{Conclusions}

The empirical results presented here represent some of the first to shed light on the causes and consequences of low take-up rates in public programs. Using a unique data set with local area detail I am able to exploit exogenous variation in factors influencing take-up in the Medicaid program to identify the reasons why families may fail to take-up benefits that involve no out of pocket costs. Costs of finding information about programs as well as costs associated with completing applications appear significant and language barriers and immigration concerns increase theses costs for Hispanic and Asian children. Furthermore, my findings suggest that increased enrollment as a result of outreach improves access to primary care as evidenced by a reduction in ambulatory care sensitive hospitalizations.

An outreach program that increases Medicaid program take-up and limits avoidable hospitalizations has the potential to reduce state expenditures substantially. Between 1997 and 2000 enrollment in non-welfare related Medicaid increased roughly 27 percent and 55 percent of the increase was due to outreach (in other words, outreach was responsible for a 15 percent increase in Medicaid enrollment, concentrated in the Hispanic and Asian communities). Considering only the charges associated with ACS hospitalizations (\$284 million in California in 1996), a 15 percent increase in Medicaid enrollment would lead to a 2.7 percent decline in ACS hospitalizations for a savings of $\$ 8$ million annually. This is six million dollars less than the costs of the campaign in the first year and excludes the (relatively small) additional costs associated with an increase in primary preventative care. This calculation, however, does not incorporate any of the potential savings associated with reduced emergency room visits, the increased labor supply of parents or the benefits to children in terms of improved health and less pain and suffering as a result of avoiding days in the hospital. Considering these savings, the benefits of the outreach program may exceed its costs. 


\section{References}

Billings, John and Nina Teicholz (1990). "Uninsured Patients in District of Columbia Hospitals," Health Affairs, 9, 158-165.

Billings, John, Zeitel, Lisa, Lukomnik, Joanne, Carey Timothy, Black, Arthur and Laurie Newman (1993). "Impact of Socioeconomic Status on Hospital Use in New York City," Health Affairs, 12, 162-173.

Bindman, Andrew, Grumbach, Kevin, Ormond, Dennis, Komaromy, Miriam, Vranizan, Karen, Lurie, Nicole, Billings, John and Anita Stewart (1995). "Preventable Hospitalizations and Access to Care,” Journal of the American Medicaid Association, 274, 305-311.

Brown, Richard and Ninze, Ponce (1999). “The State of Health Insurance in California, 1998.” UCLA Center for Health Policy Research.

Card, David and Lara Shore-Sheppard (2002). "Using Discontinuous Eligibility Rules to Identify the Effects of the Federal Medicaid Expansions on Low Income Children.” NBER Working Paper \#9058.

Craig, Peter (1991). "Costs and Benefits: A Review of Research on Take-up of Income-Related Benefits,” Journal of Social Policy, 20, 537-565.

Currie, Janet and Jonathan Gruber (1996), "Health Insurance Eligibility and Child Health: Lessons from Recent Expansions of the Medicaid Program", Quarterly Journal of Economics, 111, 431-466.

Dafny, Leemore and Jonathan Gruber (2005). "Public Insurance and Child Hospitalizations: Access and Efficiency Effects,” Journal of Public Economics, 89, 109-129.

Epstein, Andrew (2001). "The Role of Public Clinics in Preventable Hospitalizations Among Vulnerable Populations,” Health Services Research, 36, 405-410.

Fronstin, Paul (1998). "Sources of Health Insurance and Characteristics of the Uninsured: Analyses of the March 1998 Current Population Survey.” Washington D.C: Employee Benefits Research Institute Issue Brief.

Gadmoski, Anne, Jenkins, Paul, and Melissa Nichols (1998). "Impact of a Medicaid Primary Care Provider and Preventive Care on Pediatric Hospitalization,” Pediatrics, 101, 1-10.

Gill, James and Arch Mainous, “The Role of Provider Continuity in Preventing Hospitalizations,” Archives of Family Medicine, 7, 352-357.

Goodman, David, Stukel, Therese, and Chiang-hua Chang (1998). "Trends in Pediatric Asthma Hospitalization Rates: Regional and Socioeconomic Differences,” Pediatrics, 101, 208-213.

Graves EJ, Kozak LJ. Detailed diagnoses and procedures. National Hospital Discharge Survey, 1996. National Center for Health Statistics. Vital Health Stat 13(138). 1998.

Gruber, Jonathan (1997). “Medicaid and Uninsured Women and Children,” Journal of Economic Perspectives, 11, 199-208. 
Gruber, Jonathan (1999). “Medicaid,” NBER Working Paper \# 7829.

Hanratty, Maria (1996). “Canadian National Health Insurance and Infant Health,” American Economic Review, 86, 276-284.

Kaestner, Robert, Joyce Theodore and Andrew Racine (1999). "Does Publicly Provided Health Insurance Improve the Health of Low-Income Children in the US?” NBER Working Paper \#6887.

Kaestner, Robert, Joyce Theodore and Andrew Racine (2001). "Medicaid Eligibility and the Incidence of Ambulatory Care Sensitive Hospitalizations for Children.” Social Science and Medicine, 52,305-13.

Kasper, Judith (1986). "Health Status and Utilization: Differences by Medicaid Coverage and Income,” Health Care Financing Review, 7,1-17.

MediCal Policy Institute [2002]. "Using Market Research to Improve Enrollment of Families Eligible for Medi-Cal and Healthy Families.”

McConnochie, Kenneth, Roghmann, Klaus, and Grgeory Liptak (1997). “Socioeconomic Variation in Discretionary and Mandatory Hospitalization of Infants: An Ecological Analysis," Pediatrics, 99, 774-784.

Parchman, Michael and Steven Culler (1994). "Primary Care Physicians and Avoidable Hospitalizations,” Journal of Family Practice, 39, 123-128.

Parker, Jennifer and Kenneth Schoendorf (2000). "Variation in Hospital Discharges for Ambulatory Care-Sensitive Conditions among Children,” Pediatrics, 106, 942-948.

Perry, Micahel (2001). "Medicaid and Healthy Families: Focus Groups with California Parents to Evaluation Medicaid and Healthy Families Programs,” Kaiser Family Foundation.

Perry, Michael, Stark, Evan and Burgiaga Valdez (1998). "Barriers to Medicaid Enrollment and Ideas for Improving Enrollment: Findings from Eight Focus Groups in California with Parents of Potentially Eligible Children,” Kaiser Family Foundation \#1436.

Remler, Dahlia, Rachlin, Jason and Sherry Glied (2001). "What Can the Take-Up of Other Programs Teach Us About How To Improve Take-Up of Health Insurance Programs?” NBER Working Paper \#8185.

Ricketts, Thomas, Randolph, Randy, Howard Hilda Ann, Pathman, Donald and Timothy Carey (2001). "Hospitalization Rates as Indicators of Access to Primary Care," Health and Place, 7, 2738.

Selden, Thomas, Banthin, JM and JW Cohen (1998). "Medicaid's Problem Children: Eligible but not Enrolled,” Health Affairs, 17,192-200. 
Shi, Leiyu, Samuels, Michael, Pease, Mary, Baily, Walter and Elizabeth Corley (1999). "Patient Characteristics Associated with Hospitalizations for Ambulatory Care Sensitive Conditions in South Carolina,” Southern Medicaid Journal, 92, 989-998.

Short, Pamela and D. Lefkowitz (1992). "Encouraging Preventive Services for Low-Income Children: The Effect of Expanding Medicaid,” Medical care, XXX, 76-80.

Stuber, Jennifer, Malloy, Kathleen, Rosenbaum, Sara and Karen Jones (2000). "Beyond Stigma: What Barriers Actually Affect the Decisions of Low-Income Families to Enroll in Medicaid?”

Center for Health Services Research and Policy, George Washington University working paper.

Weissman, Joel, Gastonis, Constantine, and Arnold Epstein (1992). "Rates of Avoidable Hospitalization by Insurance Status in Massachusetts and Maryland," Journal of the American Medicaid Association, 268, 2388-2394.

Kopczuk, Wojciech and Cristian Pop-Eleches (2005). “Electronic Filing, Tax Preparers, and Participation in the Earned Income Tax Credit.” Columbia University mimeo. 

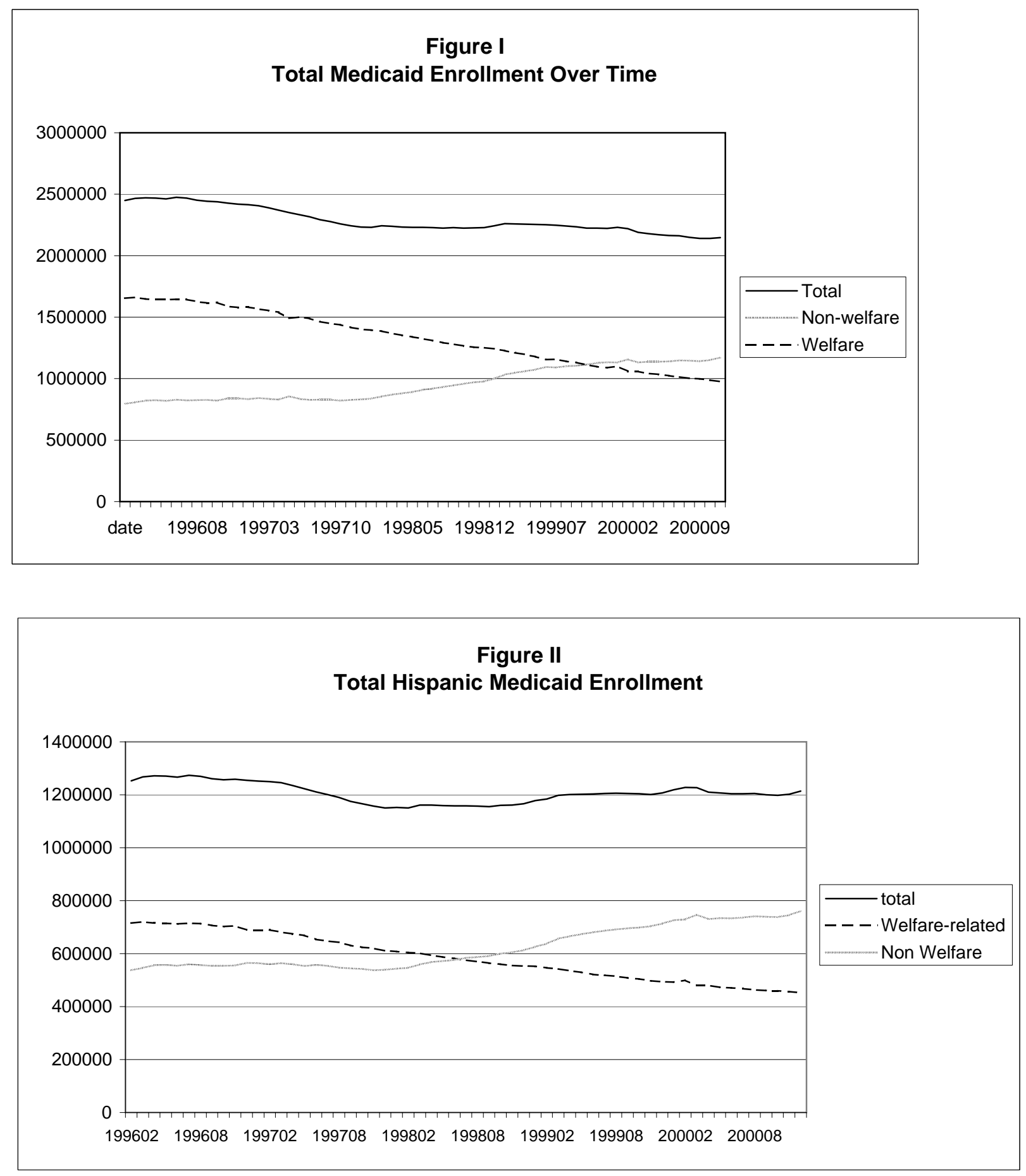


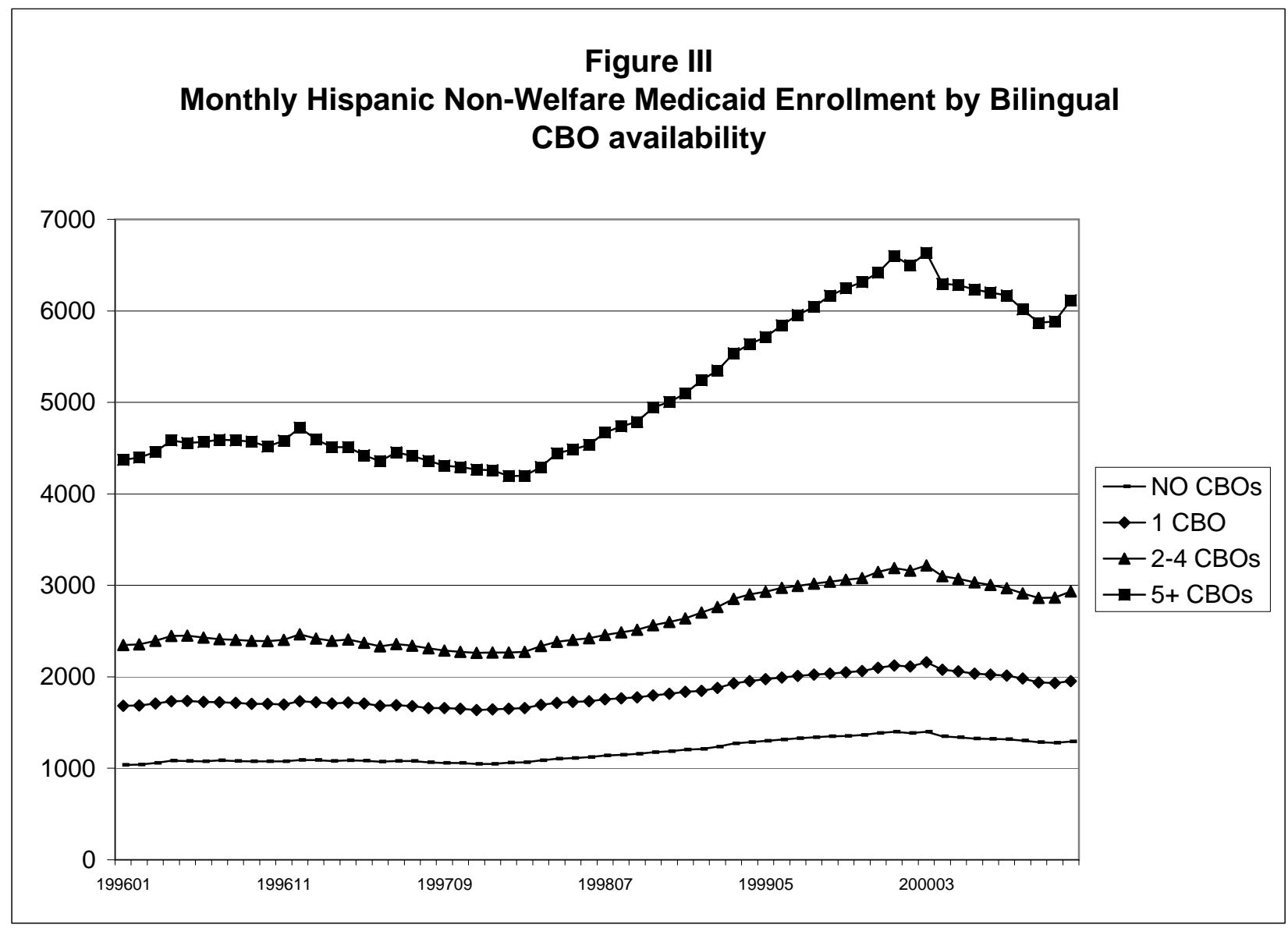

Figure IV

Monthly Births to Hispanic Women <=HS by Bilingual CBO Availability

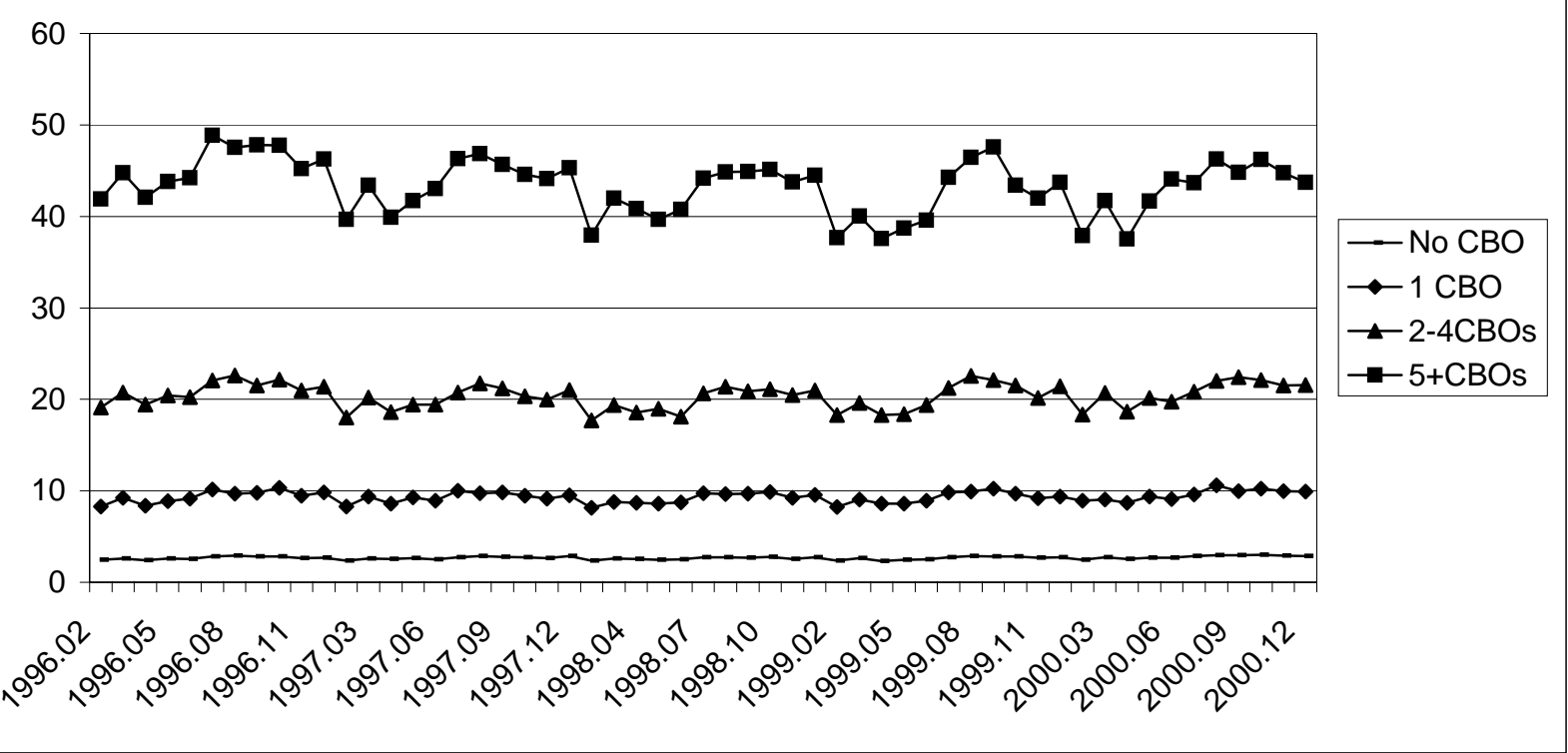


Table 1: Impact of CBOS on New Monthly Medicaid Enrollment

Blingual (Spanish) CBO*Hispanic
Blinigual (Asian) CBO *Asian
Bilingual (Spanish) CBO
Blinigual (Asian) CBO
English only CBO

Black

Hispanic

Asian

\section{Other race}

Asian*ever gain access to CBO

Hispanic*ever gain access to CBO

Observations

R-squared

Robust standard errors (clustered on zipcode) in brackets

Zipcode fixed effects

month fixed effects

zipcode*year and month fixed effects

zipcode* ${ }^{*}$ ear*month fixed effects

Non Welfare Related

\begin{tabular}{cccc}
\multicolumn{4}{c}{ Non Welfare Related } \\
\hline 12.763 & 12.72 & 12.7 & 7.517 \\
{$[1.379]$} & {$[1.388]$} & {$[1.558]$} & {$[1.379]$} \\
1.882 & 1.895 & 1.858 & 1.931 \\
{$[0.372]$} & {$[0.375]$} & {$[0.419]$} & {$[0.387]$} \\
-2.815 & -2.821 & & \\
{$[0.291]$} & {$[0.292]$} & & \\
-0.352 & -0.394 & & \\
{$[0.079]$} & {$[0.086]$} & & \\
0.027 & -0.074 & & \\
{$[0.059]$} & {$[0.067]$} & & \\
-4.705 & -4.761 & -4.774 & -4.214 \\
{$[0.177]$} & {$[0.181]$} & {$[0.204]$} & {$[0.199]$} \\
12.34 & 12.467 & 12.517 & 2.79 \\
{$[0.831]$} & {$[0.846]$} & {$[0.955]$} & {$[0.659]$} \\
-5.895 & -5.979 & -5.985 & -4.967 \\
{$[0.198]$} & {$[0.202]$} & {$[0.228]$} & {$[0.283]$} \\
-4.442 & -4.493 & -4.504 & -4.199 \\
{$[0.156]$} & {$[0.158]$} & {$[0.179]$} & {$[0.176]$} \\
& & & -1.103 \\
390379 & 390549 & 390549 & 390549 \\
0.4 & 0.41 & 0.42 & 0.47
\end{tabular}

Welfare Related

1.24

[0.308]

0.556

[0.128]

$-1.601$

[0.231]

$-1.414$

[0.185]

$-4.039$

[0.186]

$-3.903$

[0.161]

$-1.127$

[0.489]

6.965

[0.624]

390549

0.45

yes 
Table 2: Impact of CBOs on Ln(New Non Welfare Medicaid Enrollment)

$\begin{array}{lcccc} & (1) & (2) & (3) & (4) \\ \text { Blingual (Spanish) CBO*Hispanic } & 0.19 & 0.116 & 0.116 & 0.152 \\ & {[0.017]} & {[0.020]} & {[0.015]} & {[0.022]} \\ \text { Blinigual (Asian) CBO *Asian } & 0.18 & 0.137 & 0.138 & 0.173 \\ & {[0.027]} & {[0.030]} & {[0.023]} & {[0.027]} \\ \text { Bilingual (Spanish) CBO } & -0.05 & 0.022 & & 0.066 \\ & {[0.009]} & {[0.024]} & & {[0.015]} \\ \text { Blinigual (Asian) CBO } & -0.04 & -0.092 & & -0.067 \\ & {[0.008]} & {[0.021]} & & {[0.017]} \\ \text { (sum) engexist } & -0.018 & 0.049 & & 0.04 \\ & {[0.013]} & {[0.067]} & & {[0.042]} \\ \text { Black } & -0.712 & -0.697 & -0.696 & -0.873 \\ & {[0.053]} & {[0.069]} & {[0.053]} & {[0.026]} \\ \text { Hispanic } & 1.103 & 0.642 & 0.61 & 0.038 \\ & {[0.052]} & {[0.101]} & {[0.076]} & {[0.036]} \\ \text { Asian } & -0.958 & -1.135 & -1.125 & -1.058 \\ & {[0.055]} & {[0.083]} & {[0.063]} & {[0.026]} \\ \text { Other race } & -1.442 & -1.415 & -1.413 & -0.863 \\ & {[0.043]} & {[0.058]} & {[0.043]} & {[0.022]} \\ \text { Asian*ever gain access to CBO } & & 0.417 & 0.409 & 0.284 \\ & & {[0.126]} & {[0.096]} & {[0.067]} \\ \text { Hispanic*ever gain access to CBO } & & 0.749 & 0.784 & 1.254 \\ & & {[0.118]} & {[0.089]} & {[0.068]} \\ \text { Observations } & 128317 & 128317 & 128317 & 390549 \\ \text { R-squared } & 0.67 & 0.75 & 0.68 & 0.67 \\ \text { Robust standard errors (clustered on zipcode) in brackets } & & \\ \text { zipcode*year \& month fixed effects } & & & & \\ \text { zipcode*year*month fixed effects } & \text { yes } & \text { yes } & & \text { yes } \\ & & & \text { yes } & \end{array}$


Table 3: Impact of Health Provider CBOs on Monthly new Medicaid Enrollment

\begin{tabular}{|c|c|c|c|c|}
\hline & $(1)$ & $(2)$ & (3) & $(4)$ \\
\hline \multirow[t]{2}{*}{ Blingual (Spanish) CBO*Hispanic } & 23.656 & 23.598 & 23.57 & 11.517 \\
\hline & [2.462] & [2.480] & [2.783] & [2.125] \\
\hline \multirow[t]{2}{*}{ Blinigual (Asian) CBO *Asian } & 3.375 & 3.403 & 3.324 & 4.06 \\
\hline & {$[0.918]$} & {$[0.926]$} & [1.021] & [1.006] \\
\hline Bilingual (Spanish) CBO & -5.12 & $\begin{array}{r}-5.213 \\
\end{array}$ & & \\
\hline \multirow{2}{*}{ Blinigual (Asian) CBO } & -0.508 & -0.634 & & \\
\hline & [0.230] & [0.169] & & \\
\hline \multirow[t]{2}{*}{ English Only CBO } & -0.546 & -0.023 & & \\
\hline & [0.607] & [0.285] & & \\
\hline \multirow[t]{2}{*}{ Black } & -4.779 & -4.836 & -4.848 & -4.487 \\
\hline & {$[0.177]$} & [0.180] & {$[0.204]$} & [0.203] \\
\hline \multirow[t]{2}{*}{ Hispanic } & 13.651 & 13.782 & 13.834 & 7.713 \\
\hline & [0.868] & [0.883] & [0.997] & [0.781] \\
\hline \multirow[t]{2}{*}{ Asian } & -5.925 & -6.014 & -6.019 & -5.366 \\
\hline & {$[0.202]$} & {$[0.207]$} & [0.233] & [0.253] \\
\hline \multirow[t]{2}{*}{ Other race } & -4.486 & -4.539 & -4.551 & -4.359 \\
\hline & {$[0.156]$} & [0.159] & [0.179] & [0.179] \\
\hline \multirow[t]{2}{*}{ Asian*ever gain access to $\mathrm{CBO}$} & & & & -1.77 \\
\hline & & & & [1.711] \\
\hline \multirow[t]{2}{*}{ Hispanic*ever gain access to $\mathrm{CBO}$} & & & & 39.113 \\
\hline & & & & [3.955] \\
\hline Observations & 390379 & 390549 & 390549 & 390549 \\
\hline R-squared & 0.41 & 0.41 & 0.42 & 0.49 \\
\hline \multicolumn{5}{|c|}{ Robust standard errors (clustered on zipcode) in brackets } \\
\hline \multirow{5}{*}{$\begin{array}{l}\text { Zipcode fixed effects } \\
\text { year fixed effects } \\
\text { month fixed effects } \\
\text { zipcode*year and month fixed effects } \\
\text { zipcode* }{ }^{\star} \text { year*month fixed effects }\end{array}$} & yes & & & \\
\hline & yes & & & \\
\hline & yes & & & \\
\hline & & yes & & \\
\hline & & & yes & yes \\
\hline
\end{tabular}


Table 4:Impact of CBOs on New Non Welfare Medicaid Enrollment by Age

Blingual (Spanish) CBO*Hispanic
Blinigual (Asian) CBO *Asian
Bilingual (Spanish) CBO
Blinigual (Asian) CBO
English only CBO

Black

Hispanic

Asian

\section{Other race}

Asian*ever gain access to CBO

Hispanic*ever gain access to CBO

Observations

R-squared

Robust standard errors (clustered on zipcode) in brackets

Zipcode*year and month fixed effects included

\begin{tabular}{ccc} 
Infant & Age 1-5 & Age 6-18 \\
\hline-0.682 & 3.761 & 4.796 \\
{$[0.381]$} & {$[0.696]$} & {$[0.824]$} \\
0.775 & 1.538 & 1.813 \\
{$[0.186]$} & {$[0.287]$} & {$[0.377]$} \\
-0.061 & -2.383 & -2.591 \\
{$[0.371]$} & {$[0.606]$} & {$[0.531]$} \\
0.219 & 0.039 & -0.385 \\
{$[0.333]$} & {$[0.296]$} & {$[0.207]$} \\
-0.243 & 0.334 & 0.231 \\
{$[0.242]$} & {$[0.246]$} & {$[0.224]$} \\
-6.473 & -6.617 & -6.728 \\
{$[1.013]$} & {$[1.092]$} & {$[1.087]$} \\
5.8 & 7.564 & 8.382 \\
{$[2.005]$} & {$[2.398]$} & {$[2.776]$} \\
-4.147 & -5.028 & -6.878 \\
{$[0.476]$} & {$[0.592]$} & {$[0.755]$} \\
-12.244 & -13.445 & -14.879 \\
{$[1.226]$} & {$[1.324]$} & {$[1.247]$} \\
-2.211 & -1.58 & -0.531 \\
{$[1.283]$} & {$[1.351]$} & {$[1.548]$} \\
15.921 & 14.01 & 13.845 \\
{$[2.905]$} & {$[3.176]$} & {$[3.469]$} \\
279706 & 318235 & 329025 \\
0.7 & 0.73 & 0.71 \\
ind & &
\end{tabular}

\begin{tabular}{ccc} 
Infant & Age 1-5 & Age 6-18 \\
\hline-0.658 & 3.769 & 4.801 \\
{$[0.434]$} & {$[0.788]$} & {$[0.929]$} \\
0.765 & 1.505 & 1.761 \\
{$[0.208]$} & {$[0.334]$} & {$[0.430]$}
\end{tabular}

$\begin{array}{ccc}-6.463 & -6.598 & -6.71 \\ {[1.162]} & {[1.236]} & {[1.226]} \\ 5.872 & 7.632 & 8.43 \\ {[2.314]} & {[2.706]} & {[3.121]} \\ -4.162 & -5.022 & -6.881 \\ {[0.548]} & {[0.669]} & {[0.849]} \\ -12.303 & -13.421 & -14.846 \\ {[1.414]} & {[1.501]} & {[1.408]} \\ -2.198 & -1.562 & -0.488 \\ {[1.472]} & {[1.521]} & {[1.738]} \\ 15.856 & 13.948 & 13.818 \\ {[3.343]} & {[3.581]} & {[3.898]} \\ 279706 & 318235 & 329025 \\ 0.73 & 0.77 & 0.76\end{array}$


Table 5: Non-linear Impact of CBOs on New Non Welfare Enrollment: Levels and Logs

1 Spanish $\mathrm{CBO} *$ Hispanic

2 Spanish CBO*Hispanic

3 Spanish $\mathrm{CBO} * \mathrm{Hispanic}$

4 Spanish CBO*Hispanic

5 Spanish CBO*Hispanic

1 Asian Language $\mathrm{CBO}^{*} \mathrm{Asian}$

2 Asian Language $\mathrm{CBO}^{*} \mathrm{Asian}$

3 Asian Language $\mathrm{CBO} *$ Asian

4 Asian Language $\mathrm{CBO}^{\star} \mathrm{Asian}$

5 Asian Language $\mathrm{CBO}^{\star} \mathrm{Asian}$

Black

Hispanic

Asian

Other race

Asian*ever gain access to CBO

Hispanic*ever gain access to CBO

Observations

R-squared

Robust standard errors (clustered on zipcode) in brackets

Regressions include zipcode ${ }^{\star}$ year*month fixed effects

$\begin{array}{cc}11.422 & 0.343 \\ {[2.017]} & {[0.072]} \\ 30.4 & 0.794 \\ {[3.599]} & {[0.083]} \\ 39.488 & 0.891 \\ {[5.514]} & {[0.126]} \\ 62.627 & 1.052 \\ {[9.179]} & {[0.136]} \\ 86.259 & 1.444 \\ {[14.207]} & {[0.155]} \\ 2.227 & 0.271 \\ {[1.118]} & {[0.114]} \\ 5.656 & 0.61 \\ {[1.886]} & {[0.136]} \\ 5.114 & 0.686 \\ {[3.115]} & {[0.168]} \\ 5.851 & 0.973 \\ {[5.580]} & {[0.269]} \\ 16.47 & 1.525 \\ {[4.821]} & {[0.207]} \\ -4.746 & -0.496 \\ {[0.201]} & {[0.060]} \\ 12.277 & 0.574 \\ {[0.902]} & {[0.054]} \\ -5.999 & -1.194 \\ {[0.235]} & {[0.059]} \\ -4.497 & -1.611 \\ {[0.178]} & {[0.045]} \\ -1 & 0.441 \\ {[0.099]} & {[0.102]} \\ 33.434 & 1.129 \\ {[2.477]} & {[0.093]} \\ 390549 & 172406 \\ 0.42 & 0.78\end{array}$


Table 6: Impact of Advertising on New Monthly Medicaid Enrollment

\section{English Language Advertisements}

Spanish Language Advertisements

Spanish Language Advertisements*Hispanic

Lag English Language Advertisements

Lag Spanish Language Advertisements

Lag Spanish Language Advertisements*Hispanic

Lead English Language Advertisements

Lead Spanish Language Advertisements

Lead Spanish Language Advertisements*Hispanic

Black

White

Hispanic

Asian

Observations

R-squared

Robust standard errors in brackets (clustered at the DMA level)

\begin{tabular}{cccc}
$(1)$ & $(2)$ & $(3)$ & $(4)$ \\
\hline 1.764 & & & 0.808 \\
{$[1.303]$} & & & {$[0.901]$} \\
-0.677 & & & -0.609 \\
{$[0.572]$} & & & {$[0.600]$} \\
-2.689 & & & -3.786 \\
{$[2.909]$} & & & {$[3.418]$} \\
& 2.609 & & 3.175 \\
& {$[1.182]$} & & {$[1.183]$} \\
& -0.833 & & -1.508 \\
& {$[0.981]$} & & {$[1.414]$} \\
& 1.828 & & 3.475 \\
& {$[0.661]$} & & {$[1.512]$} \\
& & 0.518 & 0.104 \\
& & {$[0.334]$} & {$[0.249]$} \\
& & -0.332 & -0.765 \\
42.068 & & {$[1.268]$} & {$[0.823]$} \\
{$[6.856]$} & {$[6.853]$} & -1.065 & -0.568 \\
33.872 & 33.86 & {$[1.701]$} & {$[0.551]$} \\
{$[7.820]$} & {$[7.812]$} & {$[7.855]$} & 42.07 \\
57.247 & 56.039 & 56.82 & {$[6.855]$} \\
{$[9.018]$} & {$[8.313]$} & {$[8.768]$} & 33.868 \\
40.455 & 40.462 & 40.461 & {$[7.818]$} \\
{$[8.299]$} & {$[8.296]$} & {$[8.301]$} & 56.776 \\
336334 & 336334 & 336334 & $48.456]$ \\
0.87 & 0.87 & 0.87 & 336334 \\
& & & 0.87 \\
& & &
\end{tabular}

All regressions include zipcode*year and month dummies

Column (1) presents estimates of the impact of advertising in the current month on enrollment,

Column (2) presents estimate of the impact of advertising in the previous month on enrollment

Column (3) presents estimate of the impact of advertising in the next month on enrollment

Column (4) presents estimates of the impact of advertising in the current, previous and future month on enrollment 
Table 7: Impact of Medicaid Enrollment on Child Hospitalizations and Length of Stay (LOS)

Medicaid Enrollment

Hispanic

White

Asian

Black

Adult Hospitalizations for Same Conditions Welfare caseload

Ever Gain Access to Spanish CBO*Hispanic

Ever Gain Access to Asian CBOAsian

\section{Observations}

Robust standard errors in brackets

zipcode year and quarter fixed effects

\begin{tabular}{|c|c|c|c|c|c|c|}
\hline \multirow[b]{3}{*}{ Medica } & \multirow{2}{*}{\multicolumn{3}{|c|}{ Average LOS - All }} & \multicolumn{3}{|c|}{ Average LOS - Medicaid } \\
\hline & OLS & & IV-All & OLS & IV-Clinic & IV-All \\
\hline & -0.0002 & -0.0005 & -0.0001 & -0.0002 & -0.0005 & $\begin{array}{c}-0.0001 \\
0\end{array}$ \\
\hline Jbservations & 78844 & $\left.\begin{array}{l}{[.0004]} \\
78844\end{array}\right]$ & [0.0004] & {$\left[\begin{array}{l}0.0001] \\
60480\end{array}\right]$} & {$\left[\begin{array}{l}{[.0003]} \\
60480\end{array}\right]$} & 60480 \\
\hline & 0.28 & 0.28 & 0.28 & 0.14 & 0.14 & 0.14 \\
\hline zpcode*year \& quarter & yes & yes & yes & yes & yes & yes \\
\hline
\end{tabular}

zipcode ${ }^{\star}$ year \& quarter
zipcode $y$ year*quarter

IVC refers to IV regressions in which $\mathrm{CBOS}$ that are health providers/clinics are used as instruments in the first stage

IVA refers to IV regressions in which all CBOs are used as instruments in the first stage

$\begin{array}{lll}{[0.7617]} & {[0.8565]} & {[0.8300]} \\ 0.0515 & 0.067 & 0.051\end{array}$
Medicaid ACS Admissions
OLS IV-Clinic IV-AII

$\begin{array}{lll}-0.0014 & -0.0024 & -0.0016\end{array}$

$\left.\begin{array}{ccc}0.0006] & {[0.0010]} & {[0.0008]} \\ -0.2738 & 0.3129 & -0.1177\end{array}\right]$

$\begin{array}{ccc}-0.2738 & 0.3129 & -0.1177 \\ {[0.5609]} & {[0.8534]} & {[0.7319]}\end{array}$

$\begin{array}{ccc}-1.4979 & -1.1211 & -1.3977 \\ {[0.5599]} & {[0.6910]} & {[0.6257]} \\ {[.0852} & 0.5067 & 0.15521\end{array}$

$\begin{array}{lll}0.5578] & 0.7239] & {[0.6321}\end{array}$

$\begin{array}{lll}0.8638 & 1.1048 & 0.9279\end{array}$

$\left.\begin{array}{lll}0.0083] & 0.0408 & {[0.030}\end{array}\right][0.0082$

$\begin{array}{llll}0.0016 & 0.0019 & 0.0017\end{array}$

$\begin{array}{ccc}{[0.0005]} & {[0.0006]} & {[0.0005]} \\ -1.4873 & -1.6261 & -1.5242\end{array}$

$\begin{array}{ccc}-1.4873 & -1.6261 & -1.5242 \\ {[0.4990]} & {[0.4720]} & {[0.4886]}\end{array}$

$\begin{array}{llll}{[0.4990]} & {[0.4720]} & {[0.48861} \\ 0.7508 & 0.8346 & 0.7731\end{array}$

$[0.5099] \quad[0.5551] \quad[0.5404]$

$\begin{array}{ccc}121806 & 121806 & 121806 \\ 0.68 & 0.68 & 0.68\end{array}$

yes yes yes

\begin{tabular}{ccc}
\multicolumn{4}{c}{ All } & Marker Admissions \\
OLS & VV-Clinic & IV-All \\
-0.0001 & -0.0003 & 0 \\
{$[0.0001]$} & {$[0.0002]$} & {$[0.0002]$} \\
0.0941 & 0.2084 & 0.0545 \\
{$[0.04400$} & {$[0.1038]$} & {$[0.0981]$} \\
0.0468 & 0.1145 & 0.0199 \\
{$[0.0328]$} & {$[0.0481]$} & {$[0.0473]$} \\
0.0076 & 0.0913 & -0.0214 \\
{$[0.0304]$} & {$[0.0609]$} & {$[0.0516]$} \\
0.0149 & 0.0588 & -0.0016 \\
{$[0.0484]$} & {$[0.0427]$} & {$[0.0360]$} \\
0.0062 & 0.006 & 0.0065 \\
{$[0.0013]$} & {$[0.0011]$} & {$[0.0013]$} \\
-0.0001 & 0 & -0.0001 \\
{$[0.0000]$} & {$[0.0001]$} & {$[0.0001]$} \\
-0.0035 & -0.0294 & 0.0048 \\
{$[0.0281]$} & {$[0.0403]$} & {$[0.0416]$} \\
0.0674 & 0.0854 & 0.0615 \\
{$[0.0467]$} & {$[0.0444]$} & {$[0.0424]$} \\
121806 & 121806 & 121806 \\
0.63 & 0.64 & 0.63 \\
yes & yes & yes
\end{tabular}

All ACS Admissions

OLS IV-Clinic IV-All

$[0.0009] \quad[0.0015] \quad[0.0001$

$\begin{array}{ccc}-0.1775 & 0.7002 & 0.08 \\ 0.0278 & {[1.005]} & {[0.1370}\end{array}$

$\begin{array}{lll}0.8278] & {[1.1885]} & {[0.1376}\end{array}$

$\begin{array}{lll}-0.8092 & -0.234 & -0.6405 \\ 0.8572] & {[1.0169]} & {[0.1046}\end{array}$

$\begin{array}{ccc}0.8572] & {[1.0169]} & {[0.1046} \\ 0.2603 & 0.8921 & 0.4456\end{array}$

$\begin{array}{ccc}{[0.7263]} & {[0.9543]} & {[0.1457]} \\ 1.6785 & 2.0398 & 1.7845\end{array}$

$\begin{array}{ccc}1.6785 & 2.0398 & 1.7845 \\ {[1.0186]} & {[1.1254]} & {[0.1256]}\end{array}$

$\begin{array}{ccc}{[1.0186]} & {[1.1254]} & {[0.1256} \\ 0.0929 & 0.0898 & 0.092 \\ 0.023 & 0.012 & 0.0022\end{array}$

$\begin{array}{ccc}0.0123] & {[0.0121]} & {[0.0013} \\ 0.0021 & 0.0026 & 0.0022 \\ 0.000 & 10.006 & {[0.0001}\end{array}$

$0.0005] \quad[0.0006] \quad[0.0001$

$\begin{array}{lll}-1.5649 & -1.7747 & -1.6264 \\ 0.6155] & {[0.5899]} & {[0.1783}\end{array}$

$\begin{array}{ccc}-10.6155] & {[0.5889]} & {[0.1783} \\ 0.7932 & 0.9153 & 0.829\end{array}$

$[0.6670] \quad[0.7104] \quad[0.1163$

$\begin{array}{ccc}121806 & 121806 & 121806 \\ 0.81 & 0.81 & 0.81\end{array}$

yes yes yes

\begin{tabular}{|c|c|c|c|c|c|}
\hline \multicolumn{3}{|c|}{ Average LOS - All } & \multicolumn{3}{|c|}{ Average LOS - Medicaid } \\
\hline OLS & IV-Clinic & IV-All & OLS & IV-Clinic & IV-All \\
\hline-0.0002 & -0.0002 & 0.0001 & -0.0002 & -0.0003 & 0 \\
\hline [0.0001] & {$[0.0004]$} & [0.0002] & [0.0001] & [0.0004] & \\
\hline 78844 & 78844 & 78844 & 60480 & 60480 & 60480 \\
\hline & 0.73 & 0.73 & & & \\
\hline
\end{tabular}

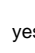

yes 
Appendix Table 1A - Changes Over Time in Access to CBOs

Zipcodes with Any CBO Zipcodes with 1 CBO

Zipcodes with 2-4 CBOs

Zipcodes with $5+$ CBOs

Zipcodes with Any CBO w/

Spanish Speaking Staff

Zipcodes with Any CBO w/

Asian Speaking Staff

\begin{tabular}{cc}
\multicolumn{2}{c}{1998} \\
\hline number & percent \\
\hline 471 & 28 \\
283 & 17 \\
171 & 10 \\
17 & 1
\end{tabular}

402

24

126

8

\begin{tabular}{cc}
\multicolumn{2}{c}{1999} \\
\hline number & percent \\
\hline 662 & 39 \\
317 & 19 \\
282 & 17 \\
63 & 4
\end{tabular}

537

32

175

10

\begin{tabular}{cc}
\multicolumn{2}{c}{2000} \\
\hline number & percent \\
\hline 776 & 46 \\
311 & 19 \\
342 & 20 \\
123 & 7
\end{tabular}

620

37

219

13

Appendix Table 1B: Changing Characteristics of Zipcodes with Access to at Least One CBO

Median Household Income

Share Urban

Share with less than a HS degree

Share Asian

Share Black

Share Hispanic

Share White
1998

33190

0.711

0.294

0.077

0.053

0.345

0.331
1999

33467

0.734

0.279

0.08

0.054

0.33

0.352
2000

34448

0.734

0.268

0.082

0.053

0.319

0.371 
Appendix Table 2: Sample Means

\begin{tabular}{|c|c|c|c|}
\hline \multirow{2}{*}{\multicolumn{4}{|c|}{ New Monthly Medicaid Enrollment }} \\
\hline & & & \\
\hline \multirow[t]{2}{*}{ New Medicaid Enrollment } & 67 & 140 & 9 \\
\hline & [100] & [117] & [10] \\
\hline \multirow[t]{2}{*}{ New Non Welfare Related Medicaid Enrollment } & 50 & 109 & 6 \\
\hline & [79] & [93] & [6] \\
\hline \multirow{2}{*}{ New Welfare Related Medicaid Enrollment } & 17 & 31 & 3 \\
\hline & [25] & [29] & [6] \\
\hline \multicolumn{4}{|l|}{ Stock of Medicaid Enrollment } \\
\hline \multirow{2}{*}{ Total Medicaid Enrollment } & 2182 & 4222 & 749 \\
\hline & [3014] & [3566] & [1000] \\
\hline \multirow{2}{*}{ Medicaid Enrollment per 1000 poor children } & 619 & 767 & 684 \\
\hline & [634] & [596] & [541] \\
\hline \multirow[t]{2}{*}{ Non Welfare Medicaid Enrollment } & 977 & 2094 & 125 \\
\hline & [1541] & [1870] & [156] \\
\hline \multirow[t]{2}{*}{ Non-Welfare Medicaid Enrollment per 1000 poor children } & 236 & 387 & 137 \\
\hline & [269] & [322] & [104] \\
\hline \multicolumn{4}{|l|}{ Hospitalizations } \\
\hline \multirow[t]{2}{*}{ ACS hospitalizations } & 10.1 & 14.8 & 2.9 \\
\hline & [14.2] & [18.4] & [3.6] \\
\hline \multirow[t]{2}{*}{ Medicaid ACS hospitalizations } & 6.8 & 10.5 & 1.5 \\
\hline & [11.1] & [14.5] & [2.6] \\
\hline \multirow[t]{2}{*}{ Medicaid ACS hospitalizations per 1000 poor children } & 1.91 & 1.7 & 1.5 \\
\hline & [3.8] & [3.5] & [3.9] \\
\hline \multirow[t]{2}{*}{ Medicaid ACS hospitalizations per 1000 Medicaid } & 10 & 2.3 & 4.3 \\
\hline & [27] & [2.9] & [30] \\
\hline \multirow[t]{2}{*}{ Marker Hospitalizations } & 0.86 & 1.04 & 0.197 \\
\hline & [1.45] & [1.41] & [.542] \\
\hline \multicolumn{4}{|l|}{ CBOs (post June 1998) } \\
\hline \multirow[t]{2}{*}{ Bilingual (Spanish Language) CBOs } & 2.1 & 2.5 & 1.6 \\
\hline & [2.4] & [2.6] & [2.2] \\
\hline \multirow[t]{2}{*}{ English Only CBOs } & 0.18 & 0.16 & 0.22 \\
\hline & {$[.53]$} & {$[.46]$} & [.54] \\
\hline \multirow[t]{2}{*}{ Bilingual (Asian Language) CBOs } & 0.55 & 0.58 & 1.3 \\
\hline & [1.5] & [1.52] & [2.7] \\
\hline \multicolumn{4}{|l|}{ Controls } \\
\hline \multirow[t]{2}{*}{$\overline{\text { Unemployment rate }}$} & 0.06 & 0.07 & 0.05 \\
\hline & {$[.04]$} & {$[.04]$} & {$[.04]$} \\
\hline \multirow[t]{2}{*}{ Per capita income } & 28912 & 28618 & 32835 \\
\hline & [7944] & [7296] & [10798] \\
\hline \multirow[t]{2}{*}{ Number of births to mothers $<=\mathrm{HS}$} & 21 & 44 & 4 \\
\hline & [31] & [36] & [5] \\
\hline
\end{tabular}


Appendix Table 3: First Stage Results Impact of CBOs on Stock of Medicaid Enrollment

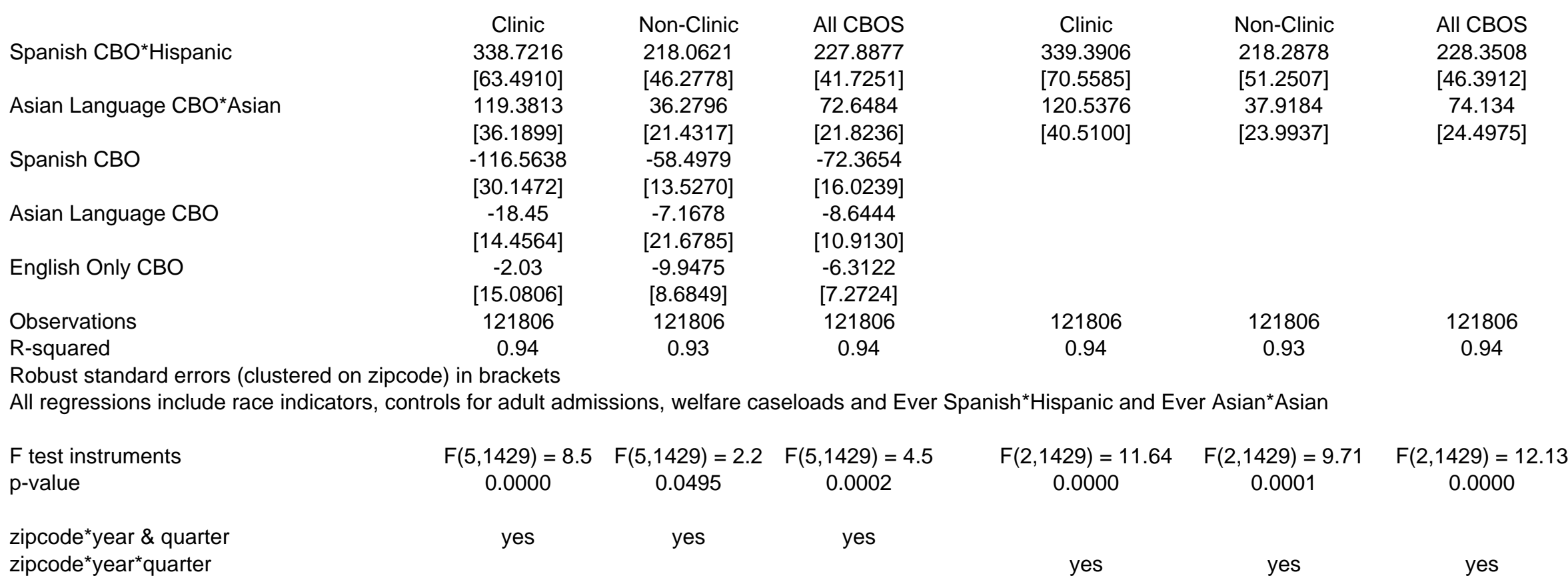

